\title{
Reinforcing Effect of a Thin Basalt Fiber-reinforced Polymer Plywood Coating
}

\begin{abstract}
Samuel Kramár,* and Pavel Král
The strengthening effect of basalt fiber-reinforced epoxy coatings was investigated with regard to their areal weight and position on the compression or tension side of plywood. Beach plywood was coated on one side with a basalt fiber-reinforced epoxy matrix. Two biaxial and one twilled fabric with areal weights of $170 \mathrm{~g} / \mathrm{m}^{2}, 210 \mathrm{~g} / \mathrm{m}^{2}$, and $340 \mathrm{~g} / \mathrm{m}^{2}$ respectively were used. The thickness of the plywood was $21 \mathrm{~mm}$. The results showed the best reinforcing effect was obtained with the highest weight when mounted on the tension side of the parallel specimens. The bending strength of these specimens was improved by $15.7 \%$. The perpendicular specimens were positively reinforced by the fiber-reinforced polymers on both the compression and tension sides. The tension reinforcement provided a higher deflection, which was further analyzed using digital image correlation. The evaluated data indicated significant displacement of the neutral axis. The impact strength of the parallel specimens was not improved by the reinforcement, but all of the reinforced perpendicular specimens were significantly strengthened.
\end{abstract}

Keywords: Basalt fibers; BFRP; Plywood strengthening; Plywood coating

Contact information: Department of Wood Science, Faculty of Forestry and Wood Technology, Mendel University in Brno, Zemédèlská 1, 61300 Brno, Czech Republic;

*Corresponding author: samuel.kramar@mendelu.cz

\section{INTRODUCTION}

Basalt is a naturally abundant material of volcanic origin, and its processing is environmentally friendly and does not require any additives (Raj et al. 2017). Basalt has been proposed as a possible replacement for asbestos (Singha 2012) because of its benign nature towards humans (McConnell et al. 1994). Processing basalt has seen continuous decreases in production costs (Artemenko and Kadykova 2008), which makes it less expensive than glass fibers (Novitskii 2004). The density of basalt, at $2.7 \mathrm{~g} / \mathrm{cm}^{3}$ to 2.9 $\mathrm{g} / \mathrm{cm}^{3}$ (Novitskii 2004; Singha 2012), is comparable to the density of glass, at $2.6 \mathrm{~g} / \mathrm{cm}^{3}$ (Joshi et al. 2004). E-glass fibers have a modulus of elasticity (MOE) as high as $70 \mathrm{GPa}$, whereas the MOE of basalt fibers reaches as high as $110 \mathrm{GPa}$ (Novitskii 2004). Lopresto et al. (2011) found that the Young's modulus of basalt fiber-reinforced polymers (BFRP) is approximately $40 \%$ higher than that of E-glass fiber-reinforced polymers (GFRP). However, Liu et al. (2006) did not find any remarkable differences in the mechanical properties between BFRPs and GFRPs. Fibers for strengthening purposes exhibit an ascending specific tension strength, beginning with metal fibers. This strength continues through E-glass, basalt, and S-glass fibers. Aramid fibers have even higher mechanical properties, whereas carbon fiber is the best reinforcement material currently available (Sim et al. 2005; Eker and Eker 2013). 
Fiber-reinforced polymers (FRP) have been successfully replacing traditional structural materials. Basalt has a service temperature as high as $700{ }^{\circ} \mathrm{C}$, which makes it superior to many other fibers (Novitskii 2004; Sim et al. 2005). However, basalt fiberreinforced epoxy cannot be used at these temperatures because of the low thermal resistance of epoxy resin (Richter and Steiger 2005). Elevated temperatures $\left(30{ }^{\circ} \mathrm{C}\right.$ to 80 ${ }^{\circ} \mathrm{C}$ ) can be used to notably accelerate the curing of epoxy resin during FRP production (Mravljak and Šernek 2011). Basalt, with its high thermal durability, can be recycled by pyrolysis, which incinerates the polymeric matrix at temperatures as high as $700{ }^{\circ} \mathrm{C}$ (Feih et al. 2011; Oliveux et al. 2015). For the highest strengthening effect, the outermost possible placement of FRP is recommended. A near neutral axis reinforcement does not contribute to the flexural strength (Ribeiro et al. 2009). In general, the inner layers of plywood do not have a crucial effect on the flexural properties (Kljak and Brezovic 2007), whereas a near surface mounted (NSM) FRP improves the bending strength (Xu et al. 1996).

One of the first reinforcements of plywood with glass fibers was described in a patent by Collins (1947). Another patented invention is an adhesive film reinforced with glass fibers that are used as a binder in the production of plywood (Kajander 2001). Various studies have since been conducted. Bal et al. (2015) investigated the reinforcement of poplar plywood with glass fibers and phenol-formaldehyde resin. The highest modulus of rupture (MOR) and MOE increases were determined in the perpendicular direction, whereas the specific MOR and MOE values were lower than those of the control group. Biblis and Carino (2000) overlaid pine plywood with a glass fibre-reinforced polyester resin, and the stiffness and flexural strength of the plywood were increased. According to Alhayek and Svecova (2012), reinforcing timber beams with FRP has a minimal effect on increasing the stiffness. Research has been done on the reinforcement of birch plywood with chopped carbon fiber epoxy plates bonded by a phenol-resorcinol formaldehyde resin (Xu et al. 1998), plywood strengthened with carbon fabric (Brezović et al. 2003), NSM reinforcement of plywood with graphite fiber cloth (Xu et al. 1996), and glass fibers bonded with phenol-resorcinol formaldehyde resin between layers of laminated veneer lumber (Ribeiro et al. 2009). Structural plywood overlaid with FRP can be used in transportation, for the construction of shipping containers, and in the bodies of trailers and trains. These products have potential for use as sheeting for the roofs and walls of mobile homes because of their high flexural strength and rigidity (Biblis and Carino 2000). Various types of FRP-reinforced plywood also have a future for use in wind turbine blades (Ashwill and Paquette 2008; Eker and Eker 2013) because of their good fatigue performance (Brøndsted et al. 2005).

Another approach for plywood strengthening is the use of pre-compressed veneers (Bekhta and Marutzky 2007; Gaff and Gašparík 2015) or the enhancement of poplar plywood with layers of high-density polyethylene (Fang et al. 2014). Wood-based panels can be strengthened with aluminum sheets ( $\mathrm{Lu}$ et al. 2015). Studies on plywood reinforced with basalt fibers are scarce, but there are a few studies available on basalt fiber-reinforced timber beams (de La Rosa García et al. 2013; Schober et al. 2015; de La Rosa García et al. 2016; Fernando et al. 2016; Thorhallsson et al. 2017) and BFRP cork panels (Torres et al. 2013; Hoto et al. 2014). In general, basalt in combination with wood is not well studied. Its outstanding recyclability, low price, good mechanical properties and easier production than traditional glass fibers make its use interesting for next generation materials (Fiore $e t$ al. 2015), such as reinforced wood-based panels. 
The main objective of this study was to investigate the contribution of BFRP to flexural properties of the reinforced plywood. Normally the symmetrical composition is used for the wood-based panels when reinforced with FRP. However these reinforcement are not investigated separately. The results of this study may help in further development and design of composite panels which will consider different mechanical contribution of FRP on the compressional and the tensional side. Such panels can be convenient for special applications as scaffolding or flooring on which the load is always applied only from one side.

\section{EXPERIMENTAL}

\section{Materials}

The highest quality beech plywood bonded with urea-formaldehyde resin was used in this study, which was made by DYAS.EU a.s. (Uherský Ostroh, Czech Republic). The plywood was composed of 15 layers, with an overall thickness of $21 \mathrm{~mm}$. The dimensions of the panels were $1000 \mathrm{~mm} \times 1000 \mathrm{~mm}$. Three different fabrics were used for the FRP. Two of these fabrics were plane weaved and had weights of $170 \mathrm{~g} / \mathrm{m}^{2}$ and $210 \mathrm{~g} / \mathrm{m}^{2}$. The third fabric had a twilled weave with a weight of $340 \mathrm{~g} / \mathrm{m}^{2}$. The compositions with theses fabrics were abbreviated as B1, B2, and B3, respectively. Basalt fabric was provided by Basaltex a.s. (Šmperk, Czech Republic). The reference plywood without any FRP was marked as P. The LH 385 epoxy resin and H 146 hardener were provided by Havel Composites s.r.o. (Přáslavice, Czech Republic).

Only one layer of fabric was used for each FRP coating. The plywood panels were coated with fabrics embedded in epoxy resin using a wet layup process. The compositions were fabricated with only one surface coated with FRP. These were further distinguished according to the position during the bending tests on the variants with FRP on the compression and tension sides. The panels were hardened in a hot press at $60{ }^{\circ} \mathrm{C}$ for $4 \mathrm{~h}$ at a specific pressure of $0.3 \mathrm{MPa}$. The excessive resin was squeezed out. The composites were covered with a separation layer. After pressing, the panels were cured for the next $7 \mathrm{~d}$ until a final strength was reached. Three panels were fabricated for each composition variant.

\section{Methods}

The MOE, MOR, and deflection were measured on a ZH050/TH 3A universal testing machine (Zwick Roell AG, Ulm, Germany), according to the standard EN 310 (1990). Determination of the density as described in EN 323 (1996) was measured directly on the specimens for MOR, MOE, and impact strength (IS) prior to their testing. The results were corrected according to the density variations. Hence average values of MOR, MOE, and IS of each composition was proportionally decreased or increased to correlate with the mean density of all the panels. This data presentation will provide a better comparison, as differences caused by slight density variations were excluded. Digital image correlation (DIC) was used simultaneously with three-point bending tests. Digital image correlation was based on the comparison of photos taken by two CCD video cameras (AVT Stingray Copper F-504B, Allied Vision Technologies, Osnabrück, Germany). Monochromatic patterns made on the face of a specimen were consequently shot during testing and were evaluated to determine the 3D deformation field (André et al. 2013). Data from DIC were evaluated by VIC-3D (Correlated Solutions Inc., Columbia-SC, USA) software. The purpose of DIC was to measure the position of the neutral axis. The neutral axis is an 
interface between the compression and tension zone, which does not stay in the centroid of anisotropic material during its plastic deformation (Betts et al. 2010). Hence the DIC could provide more detailed look into the proportion of the internal deformations with the change of reinforcement's orientation. The position of neutral axis was manually measured in VIC3D software bellow the central load point as a distance from the specimen's upper surface. Impact strength testing was performed on a DPFest 400 impact machine (Labortech, Opava, Czech Republic), according to the standard CSN 490117 (1982). The orientations of the specimens for the quasi-static three-point bending and impact bending tests are shown in Fig. 1. The aim of this positioning was to separately determine the strengthening effects on the compression and tension sides.

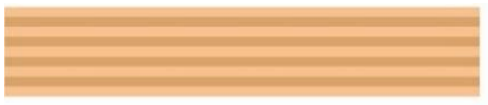

(a)

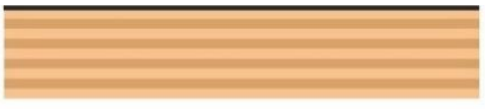

(b)

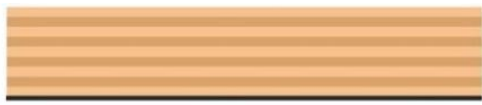

(c)

Fig. 1. FRP positions: (a) reference plywood without FRP, (b) FRP on the compression side, and (c) FRP on the tension side

Bond quality testing was performed in accordance with EN 314 (2005). However, the specimens were only conditioned in a standard environment at a $65 \%$ relative humidity and temperature of $20^{\circ} \mathrm{C}$. Internal bonding was investigated according to EN 319 (1995). These tests were used for a better understanding of the shear failure during bending. The results were compared to determine whether delamination occurred in the plywood or at the FRP-plywood interface. Both tests were performed on a ZH050 ZH050/TH 3A universal testing machine (Zwick Roell AG, Ulm, Germany). The last test examined the moisture content (EN 322 1995). The amount and position of cut specimens was done according to the EN 326-1 (1998). The whole panels were completely cut with the minimum material waste. Specimens were conditioned at a $65 \%$ relative humidity and temperature of $20{ }^{\circ} \mathrm{C}$.

The Shapiro-Wilk test was used to determine the normal distribution of the data results. Levene and Brown-Forsythe tests were used to determine the homogeneity of the variances. If the condition for homoscedasticity was fulfilled, then the data was compared via one-way analysis of variance (ANOVA) and the statistical significance was compared with Tukey's honest significant difference (HSD) test using a 95\% confidence level. If the condition of normal distribution and homogeneity of variances was not fulfilled, then the non-parametric Kruskal-Wallis test with multiple comparisons of mean ranks was used. The statistical significance was compared with a reference plywood.

\section{RESULTS AND DISCUSSION}

\section{Density and Moisture Content}

The density of the compositions increased slightly for specimens with FRP. The reference plywood had the lowest density, as no FRP was used. The increase was because of the higher density of the epoxy resin and basalt fibers. However, some deviation occurred, which was related to the variable density of the wood. The densities of the compositions are listed in Table 1. The moisture content decreased with the addition of the FRP coating and was related to the hydrophobic properties of the basalt fibers and epoxy 
matrix (Raj et al. 2017). The moisture content of the reference plywood after conditioning was $11.5 \%$. The compositions with FRP layers had a moisture content of $11.0 \%$. The plywood with a thin FRP coating is shown in Fig. 2.

Table 1. Average Density

\begin{tabular}{ccc}
\hline \multirow{2}{*}{ Composition } & \multicolumn{2}{c}{ Density $\left(\mathrm{kg} / \mathrm{m}^{3}\right)$} \\
\cline { 2 - 3 } & Mean & St. Dev. \\
\hline P & 830 & 13.7 \\
B1 & 847 & 14.2 \\
B2 & 836 & 11.4 \\
B3 & 848 & 25.0 \\
\hline
\end{tabular}

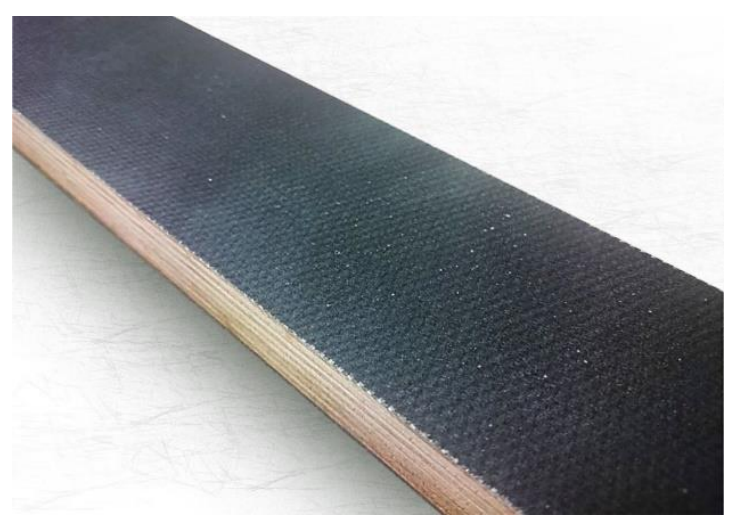

Fig. 2. Plywood specimen with a thin basalt FRP coating

\section{Modulus of Rupture, Modulus of Elasticity, and Deflection}

A significant statistical difference in the MOR for the parallel specimens (grains of the outermost veneers are parallel with the longitudinal direction of the specimen) was only found for the B3 FRP on the tension side $(p=0.0003)$. The increase in the MOR was $15.7 \%$. Compositions B2 and B3 with FRP on the tension side had a significantly lower MOE. The $p$ values of Tukey's HSD test were 0.047 and 0.018 for the B2 and B3 compositions, respectively. Tension reinforcement provided failure protection and thus increased MOR. However no pre-tensioning of BFRP was performed during fabrication of panels. If one considers that reinforcement was relatively thin, then it does not provide sufficient tensile stiffness. In this case, the thickness of specimen slightly increased, but its stiffness was the same. Hence the calculated values of MOE are decreasing with the fabric weight.

Compressive reinforcement does not provide failure protection. Yet MOR of reinforced plywood stays the same. The reinforcing effect is not significant because the surface veneers have high strength in parallel direction and BFRP is thin. An interesting finding is that the MOE is not changed either. This may be due to the fact that the BFRP had a higher modulus than wood and additionally some resin was soaked and pressed into the cells of surface veneer of plywood. These factors are possibly those that provided higher resistance to bending when they were on the compression side, compared to when they were on the tension side. 
Another effect may be caused by twill weave, which has a higher tensile strength compared to a plain one due to less crimp (Kovačević et al. 2015). The warp direction of both fabrics was always in parallel direction of surface veneer. The twill fabric had higher linear density in warp direction which can be reason of higher improvement of bending strength of parallel specimens reinforced on tension side. The average MOR and MOE values for the parallel specimens are listed in Table 2.

Table 2. Average MOR and MOE Values in the Parallel Direction

\begin{tabular}{cccccc}
\hline \multirow{2}{*}{ Composition } & \multirow{2}{*}{ FRP Position } & \multicolumn{2}{c}{ MOR (MPa) } & \multicolumn{2}{c}{ MOE (MPa) } \\
\cline { 3 - 6 } & & Mean & St. Dev. & Mean & St. Dev. \\
\hline P & No FRP & 83 & 4.7 & 8857 & 606 \\
\hline B1 & & 81 & 8.5 & 8319 & 811 \\
B2 & Compression side & 78 & 5.5 & 8497 & 749 \\
B3 & & 85 & 5.4 & 8784 & 596 \\
\hline B1 & & 87 & 3.6 & 8006 & 800 \\
B2 & Tension side & 89 & 4.1 & 7877 & 309 \\
B3 & & 96 & 9.1 & 7776 & 664 \\
\hline
\end{tabular}

The MOR was significantly increased for all of the perpendicular specimens (grains of the outermost veneers are perpendicular with the longitudinal direction of the specimen) containing FRP compared with that of the control plywood (Table 3). There was no statistical significance between the reinforced compositions. Improvement of MOR by BFRP on compression side was significant due to low mechanical properties of surface veneers in this direction. MOE of perpendicular specimens was slightly improved with BFRP on compression side too. One can use the same explanation as was for parallel specimens. In addition, the strengthening could be higher because the empty vessels are more easily compressed in transversal direction. Then the filling effect of epoxy resin could improve low transversal-tangential modulus and strength of surface veneer. Such factors, taken together, improved MOR and MOE of plywood. Reinforcement on the tension side provided protection of plywood against the fracture, thus improving its MOR. The description of detrimental effect of tension reinforcement on MOE is the same as was for the parallel specimens, since the vessel infusion with epoxy probably had no effect on the tension side, and BFRP itself was thin and without pre-tensioning.

The specimens with B3 FRP on the tension side had a lower MOR and MOE than B1 and B2 specimens with reinforcement on the same side. This finding was attributed to delamination of the FRP in most of the tested specimens. The weakest point was in the area of biggest disproportion of tensile stress, thus causing plywood and BFRP to slip relative to each other. This phenomenon occurs in plywood and timber beams with high ratio of reinforcement, where big difference in tensile stress leveled up the shear stress in their interface (Brezović et al. 2003; Kliger et al. 2007; Thorhallsson et al. 2017). Parallel specimens did not delaminate, because of the stiffness of the surface veneer, which is multiply higher in parallel than in perpendicular direction (Hering et al. 2012). The failure of the specimens with the compressive reinforcement was tensile. Therefore the specimens were not subjected to the strain that would cause delamination.

In general, the potential of the B3 tensile reinforcement was not fully utilized on parallel specimens. Once the fabric was torn from the surface, the plywood specimen was 
broken independently. Shear failure of the specimens can be seen in Fig. 3. Similar results were published by Sim et al. (2005), in which the three layers of BFRP caused shear failure or slippage, whereas beams with one or two layers of BFRP failed in the typical mode. This type of delamination contributed to the large differences observed for the tested materials and the rapid decrease in the ultimate strength. The results from the quasi-static bending tests are consistent with those of the study by Xu et al. (1998), who found that increases in the MOR for FRP-reinforced plywood were greater than those for the MOE. This behavior was attributed to the so-called hybrid effect. In some cases, the specific MOR and MOE of the strengthened plywood may have been even lower than those of the nonreinforced plywood (Bal et al. 2015) and the fabric with a lower weight or tensile strength may have an even better reinforcing effect (de La Rosa García et al. 2013). However, a thick FRP layer may have had a positive effect on the mechanical properties when the density increase was not considered (Biblis and Carino 2000).

Table 3. Average MOR and MOE Values in the Perpendicular Direction

\begin{tabular}{cccccc}
\hline \multirow{2}{*}{ Composition } & \multirow{2}{*}{ FRP Position } & \multicolumn{2}{c}{ MOR (MPa) } & \multicolumn{2}{c}{ MOE (MPa) } \\
\cline { 3 - 6 } & & Mean & St. Dev. & Mean & St. Dev. \\
\hline P & No FRP & 67 & 2.9 & 6846 & 226 \\
\hline B1 & & 79 & 5.3 & 7552 & 403 \\
B2 & Compression side & 78 & 3.6 & 7359 & 497 \\
B3 & & 75 & 6.1 & 7261 & 237 \\
\hline B1 & & 81 & 4.4 & 6982 & 477 \\
B2 & Tension side & 81 & 3.2 & 6506 & 318 \\
B3 & & 78 & 4.7 & 6210 & 466 \\
\hline
\end{tabular}

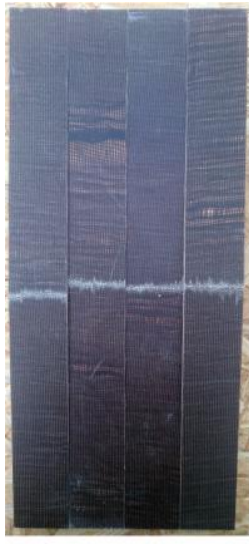

(a)



(b)

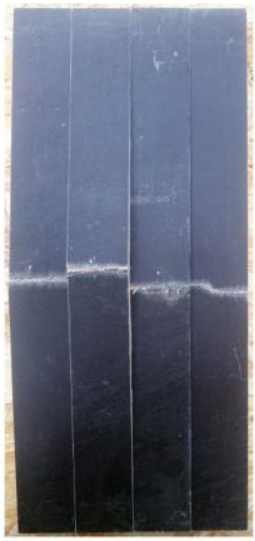

(c)

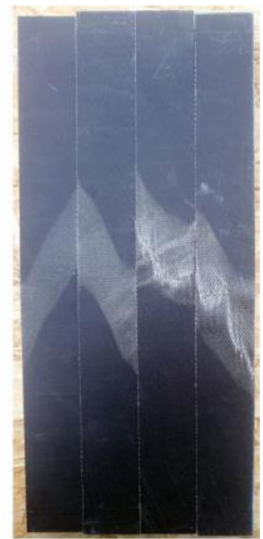

(d)

Fig. 3. Perpendicular specimens with FRP on the tension side after three-point bending: typical failures of the (a) B1, (b) B2, and (c) B3 compositions; and (d) shear failure of the B3 composition

Deflection in the parallel specimens may be divided into two groups, as there was no significant difference between the specimens. The first group contained specimens with FRP on the compression side and the reference plywood. The second group contained specimens with FRP on the tension side. The first group reached an average deflection of $16.5 \mathrm{~mm}$. The average deflection of the second group was $22 \mathrm{~mm}$, and the highest average 
deflection occurred in the B3 specimen at $22.9 \mathrm{~mm}$. A graphical comparison is shown in Fig. 4.

The perpendicular specimens exhibited higher deflection values than the parallel specimens. This was related to the grain direction of the surface veneers and the FRP supporting the wood against its ultimate rupture on the tension side (Thorhallsson et al. 2017). Here, the specimens were divided into two groups again. The first group contained specimens with FRP on the compression side and the reference plywood, with an average deflection of $18.9 \mathrm{~mm}$. The second group contained specimens with FRP on the tension side, with an average deflection of $23.9 \mathrm{~mm}$. The highest average deflection of $25 \mathrm{~mm}$ was measured with the B2 specimens. A graphical comparison of the specimens is shown in Fig. 5.



Fig. 4. Individual MOR-deflection values of the parallel specimens

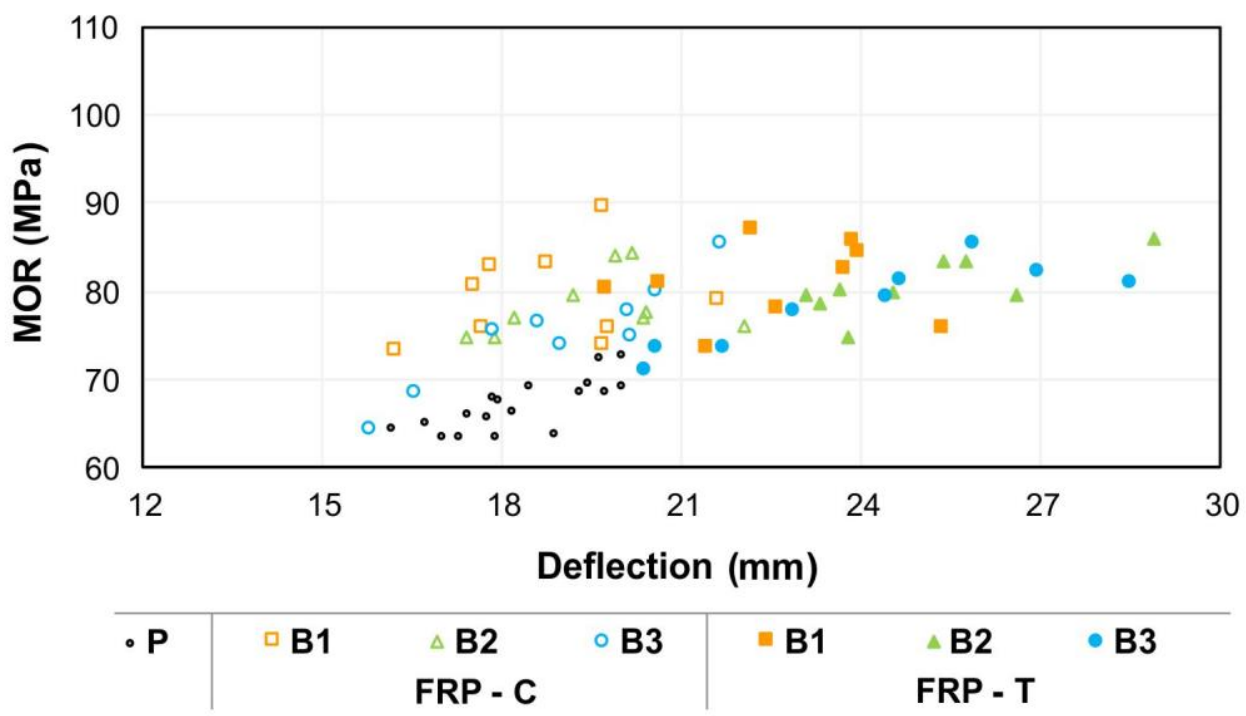

Fig. 5. Individual MOR-deflection values of the perpendicular specimens 
The results were in accordance with those from Sim et al. (2005), who found that the basalt fibers provided a good ductile behavior, which resulted in higher possible deflections. Hoto et al. (2014) compared flax and basalt fibers for various NSM FRP on the compression and tension sides of cork panels. These results showed a higher specimen deflection with BFRP on the tension side.

The neutral axis displacement was evaluated by a one-way ANOVA. The composition with FRP on the tension side exhibited a significant displacement of the neutral axis towards the tension side at the maximum force $\left(F_{\max }\right)$. This behavior was caused by the basalt fibers, which prevented tension failure of the wood. Figure 6 shows the neutral axis displacement of the parallel specimens, and Fig. 7 shows the displacement of the perpendicular specimens.

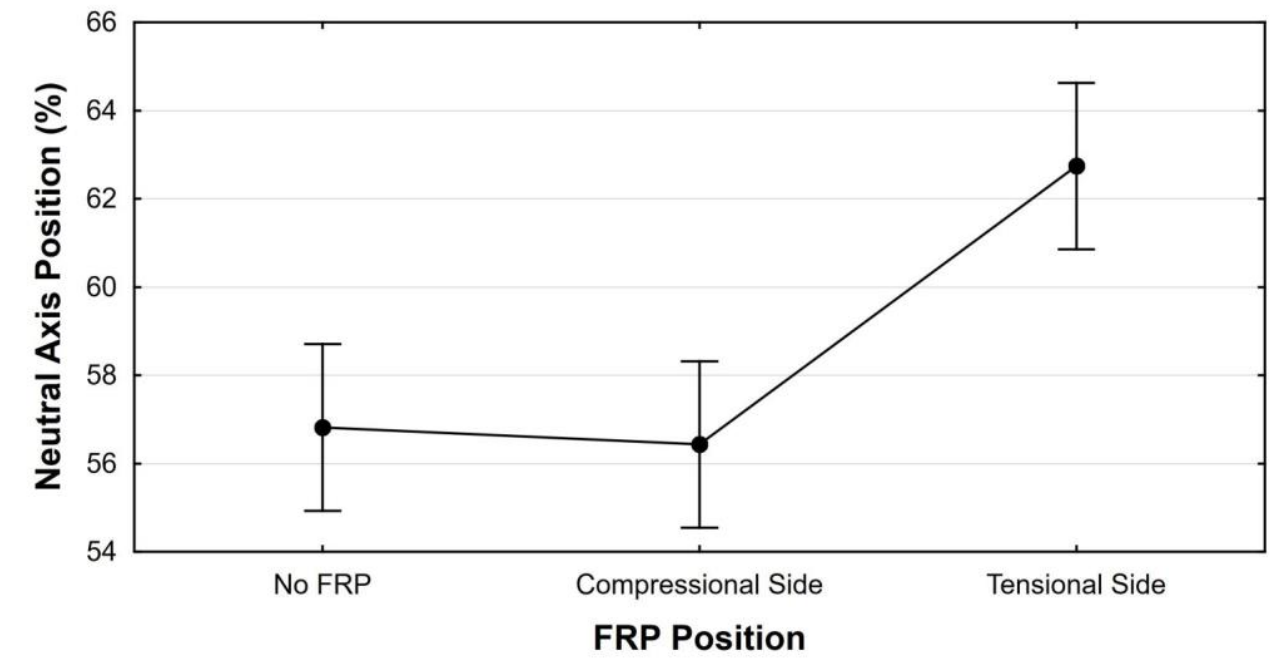

Fig. 6. Neutral axis position of the parallel specimens at the $F_{\max }$

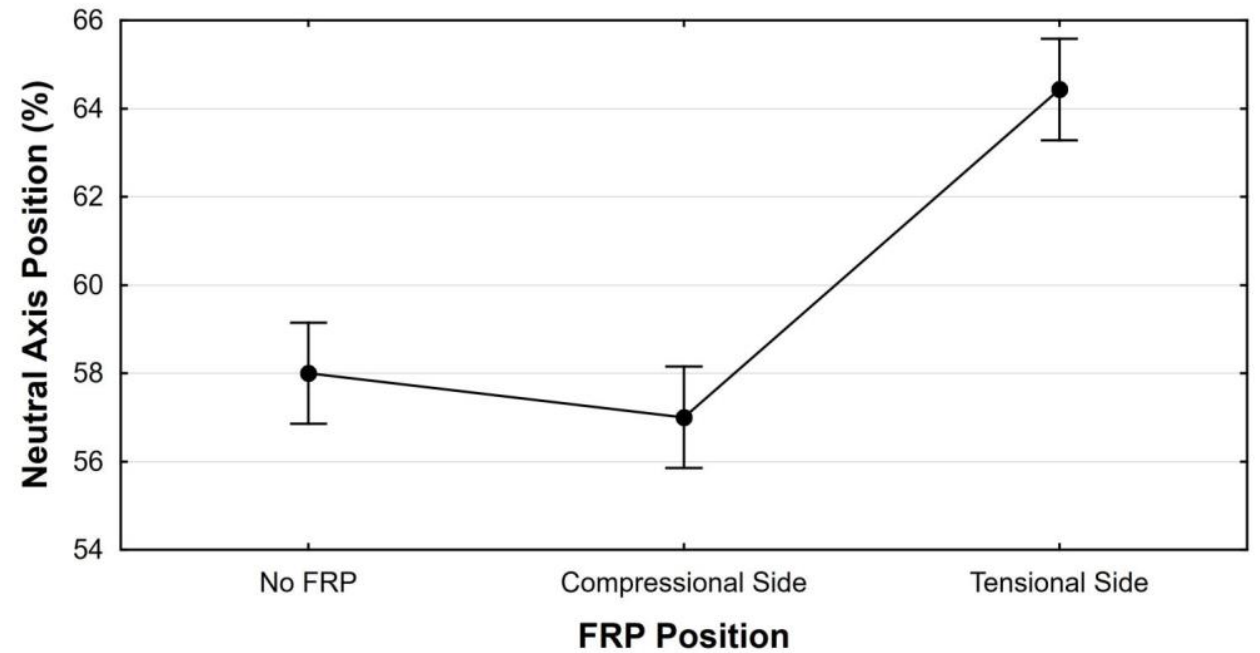

Fig. 7. Neutral axis position of the perpendicular specimens at $F_{\max }$

In general, the neutral axis displacement of the perpendicular specimens was higher when compared with that of the parallel specimens. Only the compositions with FRP on the tension side had statistically significant displacement of the neutral axis compared with 
that of the other compositions. The deformation and neutral axis positions are shown in the DIC images in Fig. 8, where (a) is a parallel specimen with the FRP on the compression side and the neutral axis located at $52 \%$ of the cross section; (b) is a parallel specimen with the FRP on the tension side and the neutral axis located at $66 \%$ of the cross section; (c) is a perpendicular specimen with the FRP on the compression side and the neutral axis located at 55\% of the cross section; and (d) is a perpendicular specimen with the FRP on the tension side and the neutral axis located at $69 \%$ of the cross section.

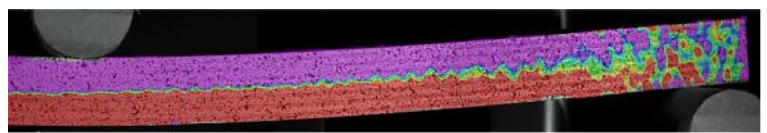

(a)

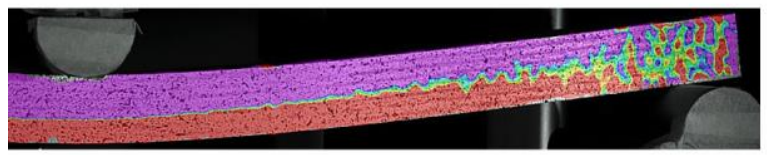

(b)

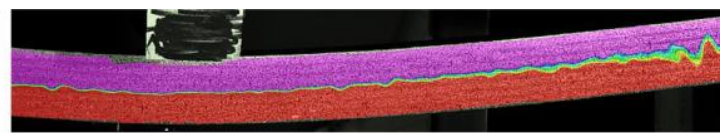

(c)

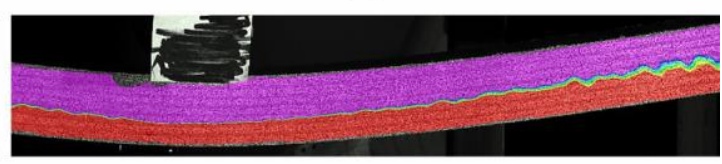

(d)

Compression zone

Neutral axis

Tension zone

Fig. 8. Neutral axis position of parallel $(a, b)$; and perpendicular (c, d) specimens; with FRP on the compression $(a, c)$; and the tension $(b, d)$ side

\section{Impact Strength}

The Kruskal-Wallis test showed that there was no statistically significant influence of the FRP on the IS among the parallel specimens. The same results were observed for the deflection. Therefore, the IS was not improved in the parallel direction (Fig. 9). All of the perpendicular specimens had a significantly higher IS than that of the control plywood. No significant difference was observed between the compression and tension reinforcement, and the average IS increase was 54\% (Fig. 10).

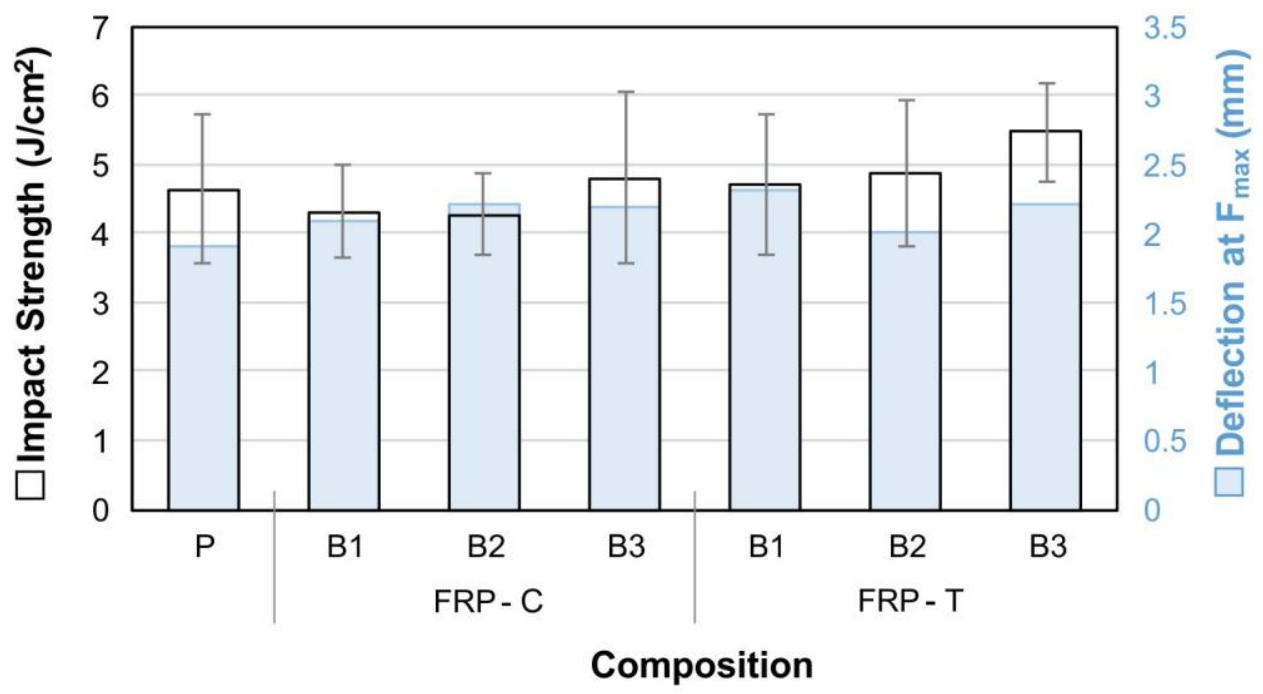

Fig. 9. IS and deflection of the parallel specimens 


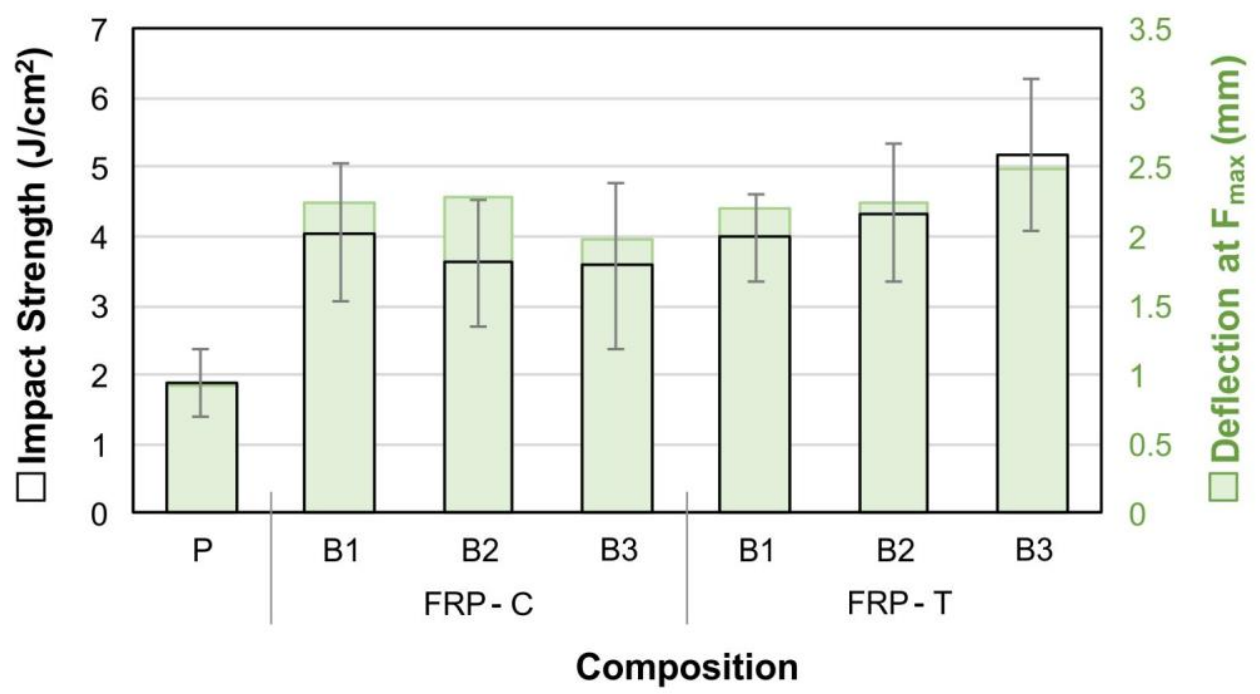

Fig. 10. IS and deflection of the perpendicular specimens

Therefore, both FRP positions had a positive strengthening effect. However, the mechanical potential of the B3 FRP cannot be fully utilized because of shear failure. Figure 11 shows slip of the reinforcement. Delamination was another reason for the higher standard deviation. After a comparison of the deflection, it was concluded that there was a significant difference for all of the reinforced compositions compared with the control plywood.

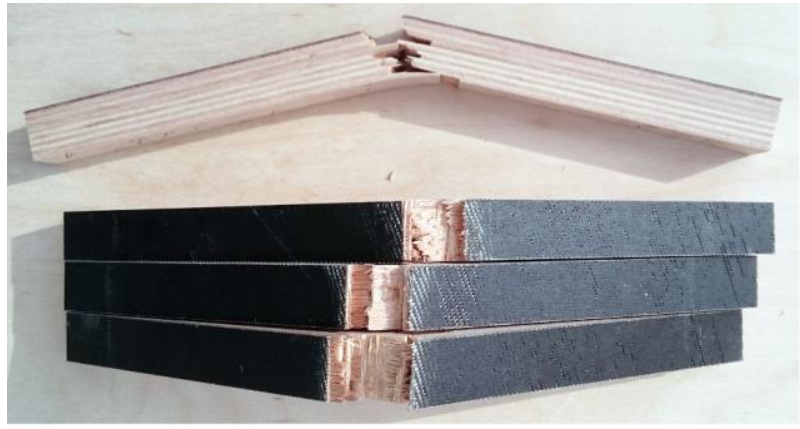

(a)



(b)

Fig. 11. Perpendicular specimens with FRP on the tension side after the IS test: (a) typical fracture and (b) shear failure of the B3 specimens

\section{Bond Quality}

The homothetic results were measured by testing the bond quality (Table 4). The tested specimens are shown in Fig. 12. The drawback of this test was the non-central position of the FRP.

The reinforcement was therefore subjected to bending, and the FRP was continuously torn from the surface of the plywood. Despite this, wood failure was observed to a high extent. 
Table 4. Average Shear Strength of the Bond Lines

\begin{tabular}{ccc}
\hline \multirow{2}{*}{ Composition } & \multicolumn{2}{c}{ Shear Strength (MPa) } \\
\cline { 2 - 3 } & Mean & St. Dev. \\
\hline P & 3.2 & 0.12 \\
B1 & 3.4 & 0.10 \\
B2 & 3.8 & 0.15 \\
B3 & 3.6 & 0.14 \\
\hline
\end{tabular}



(a)

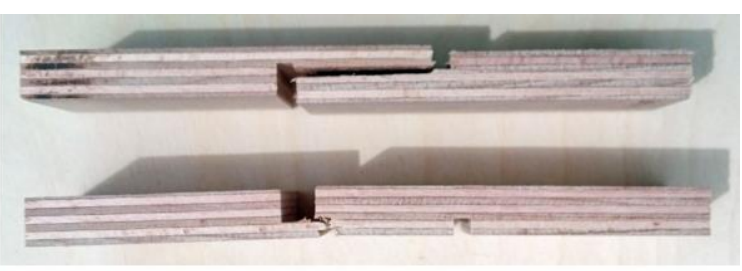

(b)

Fig. 12. Specimens after the bond quality testing: (a) B3 and (b) P compositions

\section{Internal Bonding}

The main goal of the internal bonding test was to investigate whether specimens would fail at the FRP-plywood interface of the veneer-veneer bond line. The conclusion from this test was that all of the specimens failed at the bond line of the veneers (Fig. 13).
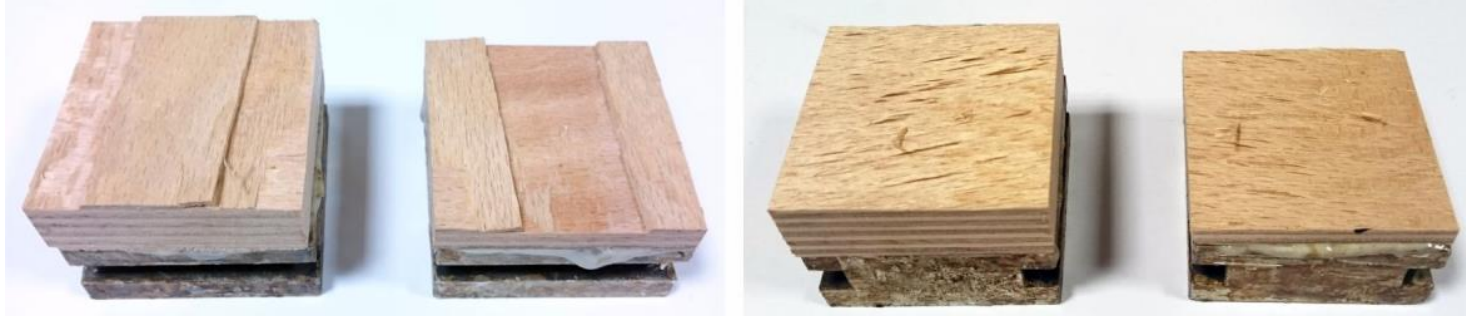

Fig. 13. Specimens after the internal bonding test



Fig. 14. Average values for the internal bonding 
Therefore, the epoxy resin created a better adhesion than that of the original UF resin used by the plywood manufacturer. The results are shown in Fig. 14. However, this adhesion was not sufficient for the BFRP-coated plywood exposed to a flexural load.

\section{CONCLUSIONS}

1. One of the main goals of this research was to investigate the mechanical contribution of basalt fiber-reinforced polymer (BFRP) on the tension and compression sides of plywood. The parallel specimens exhibited the highest increase in the modulus of rupture (MOR) with fiber-reinforced polymer (FRP) on the tension side, whereas FRP on the compression side did not significantly influence the MOR. The perpendicular specimens were reinforced with both compression and tension FRP coatings. Fabrics with various weights were investigated as well. In general, higher fabric weights resulted in higher MOR values.

2. The higher-weight fabrics decreased the modulus of elasticity (MOE) of the tensionreinforced plywood, whereas the compression placement either increased or at least did not lower the MOE. This behavior varied in the parallel and perpendicular directions. Most of the perpendicular specimens with B3 FRP on the tension side failed because of delamination, whereas debonding of the parallel specimens did not occur often. This behavior has been described in many recent studies as reinforcement slip because of differences in material strength. Therefore, one conclusion was that the low strength of the veneers in the perpendicular direction caused substantial differences in the reinforcement strength. However, the strength of the veneer in the parallel direction was higher, which resulted in infrequent debonding of the FRP.

3. The amount of fibrous reinforcement also positively contributed to the flexibility of the plywood when used on the tension side. These results were supported by digital image correlation (DIC) analysis of the neutral axis displacement. The FRP coating on the tension side significantly displaced the neutral axis towards the tension side and protected the plywood against fracture.

4. The impact strength (IS) of the parallel specimens was not improved by the FRP in any manner. However, the perpendicular specimens reinforced by FRP on either the compression or tension side exhibited a significantly higher IS than the control plywood.

5. Shear testing of the bond quality revealed that the adhesion of the FRP was similar to the adhesion between veneers. Additionally, failure in the wood occurred during this test, whereas debonding during flexural loading occurred without wood fracture. The internal bond testing indicated that adhesion of the FRP exceeded the adhesion of veneers bonded by the UF adhesive.

\section{ACKNOWLEDGMENTS}

This work was financially supported by the Internal Grant Agency (IGA) of the Faculty of Forestry and Wood Technology, Mendel University in Brno, (LDF_VP_2016009). 


\section{REFERENCES CITED}

Alhayek, H., and Svecova, D. (2012). "Flexural stiffness and strength of GFRPreinforced timber beams," J. Compos. Constr. 16(3), 245-252.

DOI: 10.1061/(ASCE)CC.1943-5614.0000261

André, A., Kliger, R., and Olsson, R. (2013). "Compression failure mechanism in smallscale wood specimens reinforced with CFRP: An experimental study," Constr. Build. Mater. 41, 790-800. DOI: 10.1016/j.conbuildmat.2012.12.038

Artemenko, S. E., and Kadykova, Y. A. (2008). "Polymer composite materials based on carbon, basalt, and glass fibres," Fibre Chem.+ 40(1), 30-32. DOI: 10.1007/s10692008-9010-0

Ashwill, T. D., and Paquette, J. (2008). "Composite materials for innovative wind turbine blades," in: SAMPE 2008, Los Angeles, CA.

Bal, B. C., Bektaş, İ., Mengeloğlu, F., Karakuş, K., and Demir, H. Ö. (2015). "Some technological properties of poplar plywood panels reinforced with glass fiber fabric," Constr. Build. Mater. 101(Part 1), 952-957. DOI: 10.1016/j.conbuildmat.2015.10.152

Bekhta, P., and Marutzky, R. (2007). "Reduction of glue consumption in the plywood production by using previously compressed veneer," Holz Roh. Werkst. 65(1), 87-88. DOI: $10.1007 / \mathrm{s} 00107-006-0142-8$

Betts, S. C., Miller, T. H., and Gupta R. (2010). "Location of the neutral axis in wood beams: A preliminary study,” Wood Mater. Sci. Eng. 5(3-4), 173-180. DOI: $10.1080 / 17480272.2010 .500060$

Biblis, E. J., and Carino, H. F. (2000). "Flexural properties of southern pine plywood overlaid with fiberglass-reinforced plastic," Forest Prod. J. 50(4), 34-36.

Brezović, M., Vladimir, J., and Stjepan, P. (2003). "Bending properties of carbon fiber reinforced plywood," Wood Res.-Slovakia 48(4), 12-24.

Brøndsted, P., Lilholt, H., and Lystrup, A. (2005). "Composite materials for wind power turbine blades," Annu. Rev. Mater. Res. 35, 505-538.

DOI: 10.1146/annurev.matsci.35.100303.110641

ČSN 490117 (1982). "Wood. Impact strength in flexure,” Bureau for standardization and testing, Prague, Czech Republic.

Collins, H. W. (1947). "Reinforced plywood," U. S. Patent No. 2428325A.

de La Rosa García, P., Escamilla, A. C., and García, M. N. G. (2013). "Bending reinforcement of timber beams with composite carbon fiber and basalt fiber materials," Compos. Part B-Eng. 55, 528-536.

DOI: 10.1016/j.compositesb.2013.07.016

de La Rosa García, P., Escamilla, A. C., and García, M. N. G. (2016). “Analysis of the flexural stiffness of timber beams reinforced with carbon and basalt composite materials," Compos. Part B-Eng. 86, 152-159.

DOI: 10.1016/j.compositesb.2015.10.003

Eker, A. A., and Eker, B. (2013). "General assessment of fiber-reinforced composites selection in wind turbine blades," in: Recent Advances in Composite Materials for Wind Turbine Blades, B. Attaf (ed.), The World Academic Publishing Co., Hong Kong, China, pp. 61-78.

EN 310 (1995). "Wood-based panels. Determination of modulus of elasticity in bending and of bending strength," European Committee for standardization, Brussels, Belgium. 
EN 314 (2005). “Plywood - Bonding quality,” European Committee for standardization, Brussels, Belgium.

EN 319 (1995). "Particleboards and fibreboards. Determination of tensile strength perpendicular to the plane of the board," European Committee for standardization, Brussels, Belgium.

EN 322 (1995). "Wood-based panels. Determination of moisture content," European Committee for standardization, Brussels, Belgium.

EN 323 (1996). “Wood-based panels. Determination of density,” European Committee for standardization, Brussels, Belgium.

EN 326-1 (1998). "Wood-based panels. Sampling, cutting and inspection. Part 1: Sampling and cutting of test pieces and expression of test results," European Committee for standardization, Brussels, Belgium.

Fang, L., Chang, L., Guo, W.-j., Chen, Y., and Wang, Z. (2014). "Influence of silane surface modification of veneer on interfacial adhesion of wood-plastic plywood," Appl. Surf. Sci. 288, 682-689. DOI: 10.1016/j.apsusc.2013.10.098

Feih, S., Boiocchi, E., Mathys, G., Mathys, Z., Gibson, A. G., and Mouritz, A. P. (2011). "Mechanical properties of thermally-treated and recycled glass fibres," Compos. Part B-Eng. 42(3), 350-358. DOI: 10.1016/j.compositesb.2010.12.020

Fernando, D., Frangi, A., and Kobel, P. (2016). "Behaviour of basalt fibre reinforced polymer strengthened timber laminates under tensile loading," Eng. Struct. 117, 437456. DOI: 10.1016/j.engstruct.2016.03.009

Fiore, V., Scalici, T., Di Bella, G., and Valenza, A. (2015). "A review on basalt fibre and its composites," Compos. Part B-Eng. 74, 74-94.

DOI: 10.1016/j.compositesb.2014.12.034

Gaff, M., and Gašparík, M. (2015). "Influence of densification on bending strength of laminated beech wood," BioResources 10(1), 1506-1518.

DOI: $10.15376 /$ biores.10.1.1506-1518

Hering, S., Keunecke, D., and Niemz, P. (2012). "Moisture-dependent orthotropic elasticity of beech wood," Wood Sci. Technol. 46(5), 927-938.

DOI: $10.1007 / \mathrm{s} 00226-011-0449-4$

Hoto, R., Furundarena, G., Torres, J. P., Muñoz, E., Andrés, J., and García, J. A. (2014). "Flexural behavior and water absorption of asymmetrical sandwich composites from natural fibers and cork agglomerate core," Mater. Lett. 127, 48-52.

DOI: 10.1016/j.matlet.2014.04.088

Joshi, S. V., Drzal, L. T., Mohanty, A. K., and Arora, S. (2004). "Are natural fiber composites environmentally superior to glass fiber reinforced composites?," Compos. Part A-Appl. S. 35(3), 371-376. DOI: 10.1016/j.compositesa.2003.09.016

Kajander, R. E. (2001). "Wood laminate and method of making," U. S. Patent No. 6331339B1.

Kliger, R., Al-Emrani, M., Johansson, M., and Crocetti, R. (2007). "Strengthening glulam beams with steel or cfrp plates," Proc. Asia-Pacific Conf. FRP Struct. (APFIS 2007), 291-296.

Kljak, J., and Brezovic, M. (2007). "Relationship between bending and tensile stress distribution in veneer plywood," Forest Prod. J. 57(12), 65-69.

Kovačević, S., Brnada, S., and Dubrovski, P. D. (2015). "Analysis of the mechanical properties of woven fabrics from glass and basalt yarns," Fibres Text. East. Eur. 23(6), 83-91. DOI: 10.5604/12303666.1167424 
Liu, Q., Shaw, M. T., Parnas, R. S., and McDonnell, A.-M. (2006). "Investigation of basalt fiber composite mechanical properties for applications in transportation." Polym. Composite. 27(1), 41-48. DOI: 10.1002/pc.20162

Lopresto, V., Leone, C., and De Iorio, I. (2011). "Mechanical characterisation of basalt fibre reinforced plastic," Compos. Part B-Eng. 42(4), 717-723.

DOI: 10.1016/j.compositesb.2011.01.030

Lu, K., White, R. H., Fu, F., Hou, J., Zhang, Y., Gribbins, N., and Cai, Z. (2015). "Reinforced hybrid wood-aluminum composites with excellent fire performance," Holzforschung 69(8), 1027-1037. DOI: 10.1515/hf-2014-0099

McConnell, E. E., Kamstrup, O., Musselman, R., Hesterberg, T. W., Chevalier, J., Miiller, W. C., and Thevenaz, P. (1994). "Chronic inhalation study of size-separated rock and slag wool insulation fibers in Fischer 344/N rats," Inhal. Toxicol. 6(6), 571614. DOI: $10.3109 / 08958379409003042$

Mravljak, M., and Šernek, M. (2011). "The influence of curing temperature on rheological properties of epoxy adhesives," Drvna Ind. 62(1), 19-25.

DOI: $10.5552 /$ drind.2011.1042

Novitskii, A. G. (2004). "High-temperature heat-insulating materials based on fibers from basalt-type rock materials," Refract. Ind. Ceram.+ 45(2), 144-146.

DOI: 10.1023/B:REFR.0000029624.43008.ef

Oliveux, G., Dandy, L. O., and Leeke, G. A. (2015). "Current status of recycling of fibre reinforced polymers: Review of technologies, reuse and resulting properties," Prog. Mater. Sci. 72, 61-99. DOI: 10.1016/j.pmatsci.2015.01.004

Raj, S., Kumar, V. R., Kumar, B. H. B., and Iyer, N. R. (2017). "Basalt: Structural insight as a construction material," Sādhanā 42(1), 75-84. DOI: 10.1007/s12046-016-0573-9

Ribeiro, A. S., de Jesus, A. M. P., Lima, A. M., and Lousada, J. L. C. (2009). "Study of strengthening solutions for glued-laminated wood beams of maritime pine wood," Constr. Build. Mater. 23(8), 2738-2745. DOI: 10.1016/j.conbuildmat.2009.02.042

Richter, K., and Steiger, R. (2005). "Thermal stability of wood-wood and wood-FRP bonding with polyurethane and epoxy adhesives," Adv. Eng. Mater. 7(5), 419-426. DOI: 10.1002/adem.200500062

Schober, K.-U., Harte, A. M., Kliger, R., Jockwer, R., Xu, Q., and Chen, J.-F. (2015). "FRP reinforcement of timber structures," Constr. Build. Mater. 97, 106-118. DOI: 10.1016/j.conbuildmat.2015.06.020

Sim, J., Park, C., and Moon, D. Y. (2005). "Characteristics of basalt fiber as a strengthening material for concrete structures," Compos. Part B-Eng. 36(6-7), 504512. DOI: 10.1016/j.compositesb.2005.02.002

Singha, K. (2012). “A short review on basalt fiber," International Journal of Textile Science 1(4), 19-28. DOI: 10.5923/j.textile.20120104.02

Thorhallsson, E. R., Hinriksson, G. I., and Snæbjörnsson, J. T. (2017). "Strength and stiffness of glulam beams reinforced with glass and basalt fibres," Compos. Part BEng. 115, 300-307. DOI: 10.1016/j.compositesb.2016.09.074

Torres, J. P., Hoto, R., Andrés, J., and García-Manrique, J. A. (2013). "Manufacture of green-composite sandwich structures with basalt fiber and bioepoxy resin," $A d v$. Mater. Sci. Eng. 2013. DOI: 10.1155/2013/214506

Xu, H., Nakao, T., Tanaka, C., Yoshinobu, M., and Katayama, H. (1998). "Effects of fiber length and orientation on elasticity of fiber-reinforced plywood," J. Wood Sci. 44(5), 343-347. DOI: 10.1007/BF01130445 
Xu, H., Tanaka, C., Nakao, T., Nishino, Y., and Katayama, H. (1996). "Flexural and shear properties of fiber-reinforced plywood," Mokuzai Gakkaishi 42(4), 376-382.

Article submitted: September 20, 2018; Peer review completed: November 18, 2018; Revised version received: January 14, 2019; Accepted: January 19, 2019; Published: January 25, 2019.

DOI: 10.15376/biores.14.1.2062-2078 